\title{
Pengaruh Variasi NaOH terhadap Karakteristik Nanosilika Berbasis Batu Apung
}

\author{
Nurqori Setiawati ${ }^{(1)^{*}}$, Posman Manurung ${ }^{(1)}$ dan Simon Sembiring ${ }^{(1)}$ \\ (1)Jurusan Fisika FMIPA Universitas Lampung \\ Jl.Prof. Dr. Soemantri Brojonegoro No.1 Gedung Meneng Bandar Lampung 35145 \\ *E-mail:nurqorisetiawati@yahoo.co.id
}

Diterima (25 Maret 2018), direvisi (15 April 2018)

\begin{abstract}
Nanoparticle of silica from pumice rockhas been synthesizedby using extracted method of $\mathrm{NaOH}$ with varying of 2,5 Mand 3,5 M.The pumice was extracted using $\mathrm{NaOH}$, silica titration using $\mathrm{H}_{2} \mathrm{SO}_{4}$ and purification of silica using $\mathrm{HCl}$. The solution was calcination at $700^{\circ} \mathrm{C}$ for 2 hours. The XRD result showed that diffraction pattern of amorphous silica. The EDS result confirmed the purity of silica for $\mathrm{NaOH} 3,5 \mathrm{M}$ were $75,84 \%$. Particle size from TEM result is(11,32 $\pm 0,922) \mathrm{nm}$ for $\mathrm{NaOH} \mathrm{3,5} \mathrm{M.} \mathrm{The} \mathrm{surface} \mathrm{area} \mathrm{for}$ $\mathrm{NaOH}$ of 2,5 $\mathrm{M}$ and $3,5 \mathrm{M}$ are $178,7 \mathrm{~m}^{2} / \mathrm{g}$ and $186,2 \mathrm{~m}^{2} / \mathrm{g}$ respectively.
\end{abstract}

Keywords :pumice, nanosilica, $\mathrm{NaOH}$ and surface area.

Abstrak. Nanopartikel silica berbasis batu apung telah disintesis menggunakan metode ekstraksi dengan variasi $\mathrm{NaOH} 2,5 \mathrm{M}$ dan 3,5M. Batu apung yang telah dipreparasi kemudian diekstraksi menggunakan $\mathrm{NaOH}$, titrasi menggunakan $\mathrm{H}_{2} \mathrm{SO}_{4}$ dan pemurnian menggunakan $\mathrm{HCl}$. Setelah itu sampel dikalsinasi pada suhu $700^{\circ}$ Cselama 2 jam. Hasil XRD menunjukkan bahwasilika yang dihasilkan secara umum adalah fasa amorf. Hasil EDS memberi informasi bahwa kemurnian silika yang dihasilkan untuk $\mathrm{NaOH} 3,5 \mathrm{M}$ sebesar 75,84\%. Ukuran partikel yang dihasilkan dari hasil TEM sebesar 11,74 $\pm 0,92 \mathrm{~nm}$ pada $\mathrm{NaOH} 3,5 \mathrm{M}$. Nanosilika yang dihasilkan memiliki luas permukaan sebesar 178,7 $\mathrm{m}^{2} / \mathrm{g}$ pada $\mathrm{NaOH} 2,5 \mathrm{M}$ dan 186,2 $\mathrm{m}^{2} / \mathrm{g}$ pada $\mathrm{NaOH} 3,5$ $\mathrm{M}$ dari hasil BET.

Kata kunci: batuapung, nanosilika, $\mathrm{NaOH}$ dan luas permukaan

\section{PENDAHULUAN}

Silika merupakan senyawa kimia dengan beberapa karakteristik khusus diantaranya bahan dielektrik yang sangat baik, bersifat stabil secara kimia, tahan terhadap asam dan basa dan memiliki karakteristik insulator yang baik [1]. Dengan karakteristik tersebut, silika banyak diaplikasikan dalam berbagai bidang diantaranya bidang industri, bidang elektronik, dan bidang kesehatan [2].

Silika dapat diperoleh dari nabati, sintesis dan mineral. Silika nabati biasanya diperoleh dari tumbuh-tumbuhan dengan aplikasi yang cukup luas. Sedangkan silika sintesis merupakan silika yang banyak dijual dipasaran dan memiliki kekurangan yaitu harganya yang relatif mahal [3]. Alternatif lain untuk mendapatkan silika yaitu dengan silika mineral. Silika mineral merupakan silika yang banyak dihasilkan dari proses pertambangan yang memiliki banyak mineral. Mineral-mineral tersebut berasal dari batuan beku yang mudah didapatkan di daerah gunung berapi. Indonesia khususnya Lampung merupakan salah satu lokasi yang terdapat gunung berapi dan menghasilkan banyak batuan beku. Salah satu batuan beku yang paling banyak dihasilkan yaitu batu apung [4]. 
Kandungan silika dalam batu apung mendekati $60 \%$.

Penelitian terdahulu terkait silika dari batuan yaitu penelitian [5] yang menggunakan batu perlit. Metode yang digunakan yaitu pelarutan dengan $\mathrm{NaOH}$ pada suhu kamar. Hasilnya yaitu berupa serbuk silika amorf. Kemudian penelitian [6], batu apung dilarutkan dengan $\mathrm{NaOH} 2$ M, kemudian residu yang dihasilkan dikalsinasi pada suhu $750{ }^{\circ} \mathrm{C}$, silika yang dihasilkan masih berupa amorf. Namun penelitian-penelitian tersebut belum mendapatkan silika dengan ukuran nano. Penelitian terkait silika nano yaitu [7] menghasilkan silika amorf berukuran nano (8 - $10 \mathrm{~nm})$ dari ekstraksi abu dengan konsentrasi $\mathrm{NaOH}$ yang digunakan $2 \mathrm{M}$. Dengan beberapa referensi tersebut $\mathrm{NaOH}$ dengan konsentrasi molar yang sama memiliki karakteristik silika yang berbeda, namun belum termasuk dalam hal mendapatkan silika berbasis batuan berskala nano. Silika dengan ukuran nano lebih fleksibel jika diaplikasikan salah satunya yaitu sebagai penyangga untuk fotokatalis [8].

Atas dasar latar belakang yang dikemukakan, penelitian ini mempelajari lebih lanjut terkait pengaruh variasi $\mathrm{NaOH}$ terhadap karakteristik silika berbasis batu apung. Batu apung yang diteliti berasal dari daerah pantai Pasir Putih Lampung Selatan. Metode yang digunakan menggunakan metode ekstraksi [5] dengan penggunaan suhu $100{ }^{\circ} \mathrm{C}$ pada variasi konsentrasi $\mathrm{NaOH}$ selama proses ekstraksi.

\section{METODE PENELITIAN}

Bahan yang digunakan dalam penelitian ini adalah batuapung pantai Pasir Putih Lampung Selatan, $\mathrm{NaOH}$ 99\% (Merck), $\mathrm{H}_{2} \mathrm{SO}_{4} 98 \%$ (JT Baker), $\mathrm{HCl} 36-$ $38 \%$ (JT Baker)danair destilasi.Peralatan yang digunakan dalam penelitian ini yaitu: kondensorrefluks, pengaduk magnet plus batang magnet, neraca digital, pompavakum, oven, mortar danalu, gelasukur, pipettetes, spatula, termometer, kertas lakmus untuk mengukur $\mathrm{pH}$ dan kertas saring.

Batu apung dicuci menggunakan air destilasi. Kemudian dikeringkan pada temperatur $80-100^{\circ} \mathrm{C}$ selama 12 jam. Setelah itu, batu apung digerus menggunakan mortar. Batu apung yang telah menjadiserbuk selanjutnya diayak menggunakan ayakan $45 \mu \mathrm{m}$ lalu dicuci dengan akuabides. Serbuk kemudian dipanaskan pada temperatur $450^{\circ} \mathrm{C}$ selama 4 jam. Serbuk kemudian disiapkan untuk proses ekstraksi.

Proses ekstraksi adalah pelarutan serbuk batu apung dengan konsentrasi $\mathrm{NaOH}$ yang berbeda untuk dua sampel. Sampel A (2,5M) dan sampel B (3,5M). Ekstraksi dilakukan dengan pemanasan 100 ${ }^{\circ}$ Csambil diputar $300 \mathrm{rpm}$ selama 24 jam. Bubur hasil ekstraksi kemudian disaring lalu dicuci dengan air destilasi yang panas. Selanjutnya dilakukan proses titrasi dengan larutan $\mathrm{H}_{2} \mathrm{SO}_{4}(5 \mathrm{M})$ hingga $\mathrm{pH}=7$. Gel hasil titrasi kemudian didiamkan pada temperature kamar selama 24 jam, lalu disaring dan dicuci dengan air destilasi. Setelah itu gel dikeringkan pada temperatur $80^{\circ} \mathrm{C}$ selama 24 jam. Gel yang telah menjadi serbuk selanjutnya dilarutkan dengan larutan $\mathrm{HCl}(1 \mathrm{M})$ pada temperatur $110^{\circ} \mathrm{C}$ selama 3 jam untuk menghilangkan pengotor. Setelah itu dilakukan filtrasi menggunakan air destilasi dan dikeringkan pada temperatur $110^{\circ} \mathrm{C}$ selama 12 jam. Serbuk kemudian kalsinasi pada temperatur $700^{\circ} \mathrm{C}$ selama 2 jam. Serbuk yang dihasilkan lalu dikarakterisasi menggunakan XRD, SEM-EDS, TEM, dan SAA metode BET. 


\section{HASIL DAN PEMBAHASAN}

\section{Hasil Analisis XRD}

Karakterisasi XRD dilakukan untuk mengetahui fasa sampel secara umum. Hasil dari analisis pola XRD kedua sampel ditunjukkan pada Gambar 1. Secara umum Gambar 1 menampilkan tipe difraktogram XRD amorf yang ditandai dengan latar belakang tinggi ke rendahberawal dari sudut $2 \theta$ sebesar $10^{\circ}$ hingga $35^{\circ}$ [6]. Terdapat beberapa puncak yang hadir dan dilakukan pencocokan data dengan data PCPDFWIN 1997. Puncak berupa mineral anortityang memiliki rumus kimia $\mathrm{CaAl}_{2}\left(\mathrm{Si}_{2} \mathrm{O}_{8}\right)$. Intensitas $2 \theta$ terbesar berada pada sudut $27,74^{\circ} ; 27,98^{\circ}$ dan $23,64^{\circ}$ (JCPDS 41-1486) untuk sampel A.

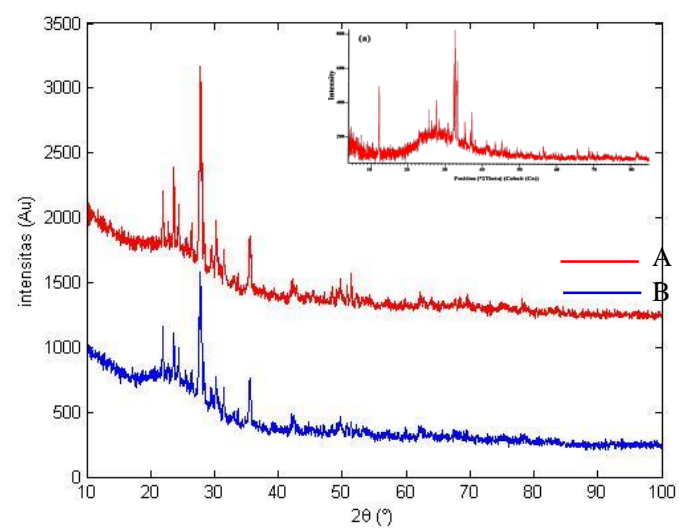

Gambar 1. Difraktogram XRD sampel A $(2,5 \mathrm{M})$ dan B (3,5M). Panjang gelombang sinar-X yang digunakan adalah 1,54 ̊.
Kemudian pada sudut $2 \theta$ sebesar $27,73^{\circ}$; $27,98^{\circ}$ dan $23,64^{\circ}$ (JCPDS 41-1486) untuk sampel B. Mineral anortit merupakan mineral pembentuk batuan terbanyak sekitar 54\% dalam kerak bumi (Rutley, 1879).

\section{Hasil Analisis SEM-EDS}

Uji SEM-EDS dilakukan pada sampel B untuk mengetahui morfologi permukaan dan kandungan sampel secara umum. Mikrostruktur sampel B ditunjukkan pada Gambar 2.

Pada Gambar 2 memperlihatkan morfologi permukaan sampel B yang menunjukkan permukaan dengan butiran yang cenderung membentuk bulatan walaupun tidak sempurna. Butiran yang ditandai dengan bulatan menandakan bahwa sampel tersebut semakin banyak memiliki pori. Kemudian hasil analisis EDS berupa komposisi kimia sampel B dapat dilihat pada Tabel 1.

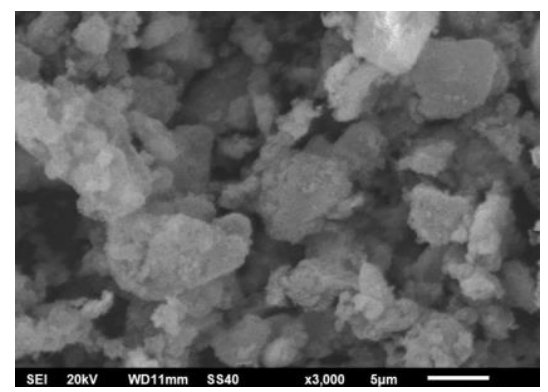

Gambar 2. Morfologi permukaan sampel B $(3,5 \mathrm{M})$.

Tabel 1.Komposisi kimia sampel B

\begin{tabular}{cccccc}
\hline Unsur & Energi $\mathrm{K} \alpha(\mathrm{KeV})$ & Massa $\%$ & Error $\%$ & Senyawa & Massa \% \\
\hline $\mathrm{C}$ & 0,277 & 16,39 & 0,48 & $\mathrm{C}$ & 16,39 \\
$\mathrm{O}$ & - & 43,31 & - & - & \\
$\mathrm{Mg}$ & 1,253 & 0,14 & 0,37 & $\mathrm{MgO}$ & 0,24 \\
$\mathrm{Al}$ & 1,486 & 1,18 & 0,38 & $\mathrm{Al}_{2} \mathrm{O}_{3}$ & 2,22 \\
$\mathrm{Si}$ & 1,739 & 35,45 & 0,42 & $\mathrm{SiO}_{2}$ & 75,84 \\
$\mathrm{Ca}$ & 3,690 & 0,57 & 044 & $\mathrm{CaO}^{2}$ & 0,80 \\
$\mathrm{Ti}$ & 4,508 & 1,87 & 0,64 & $\mathrm{TiO}_{2}$ & 3,11 \\
$\mathrm{Fe}$ & 6,398 & 1,08 & 0,89 & $\mathrm{FeO}$ & 1,39 \\
\hline
\end{tabular}


Dari Tabel 1 dapat dinformasikan bahwa senyawa silika lebih dominan yaitu sebesar 75,84\%. Ada kontaminan terbesar yaitu unsur $\mathrm{C}$. Hal ini dapat disebabkan karena kontaminasi batang magnet berunsur $\mathrm{C}$ yang direaksikan dengan $\mathrm{NaOH}$ menggunakan suhu $100{ }^{\circ} \mathrm{C}$ selama 24 jam. Seperti diketahui $\mathrm{NaOH}$ dapat merusak batang magnet berbungkus teflon. Sedangkan senyawa oksida lain merupakan senyawa yang terkandung dalam batu apung.

\section{Hasil Analisis TEM}

Analisis TEM dilakukanpada sampel Buntuk mengkonfirmasi ukuran partikel secara umum. Hasil foto TEM sampel B ditunjukkan pada Gambar 3.

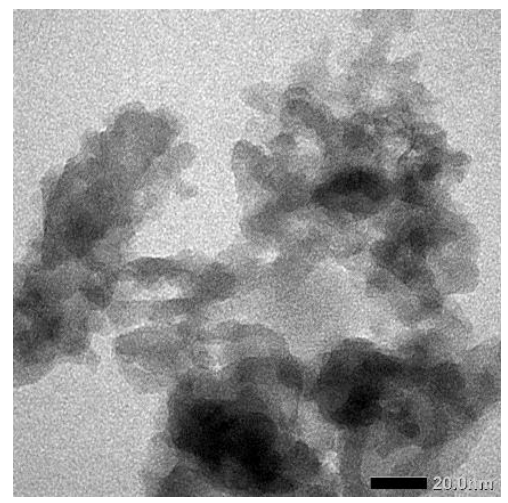

Gambar 3. Hasil TEM sampel B

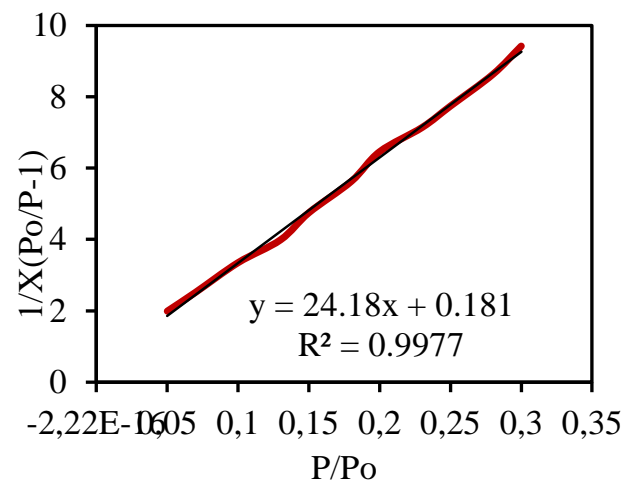

(a)
Pada Gambar 3 nano struktur sampel B yang dihasilkan tidak terlalu jelas pemisahan anatr partikel. Terdapat bagian yang terlihat terang menunjukkan bahwa partikel memiliki ketebalan lebih rendah dibandingkan dengan bagian yang terlihat gelap. Ukuran partikel yang dihasilkan sekitar $(11,32 \pm 0,922)$ nmdengan menggunakan perangkat lunak image $J$. Diketahui ada dua mekanisme dalam tampilan TEM yaitu gejala kohesif dan adhesif [10].

\section{Hasil Analisis Luas Permukaan Spesifik}

Material dengan partikel penyusun yang memiliki luas permukaan lebih besar akan lebih unggul dibandingkan dengan material limpahan. Untuk mengetahui luas permukaan spesifik dari sampel maka dilakukan uji menggunakan Surface Area Analyzer (SAA) dengan metode BET. Data hasil berupa absorpsi gas dan tekanan relatif yang di plot ke dalam persamaan BETSing, (1985). Hasil plot ditunjukkan pada Gambar 4. Kemudian data luas permukaan ditunjukkan pada Tabel 2.

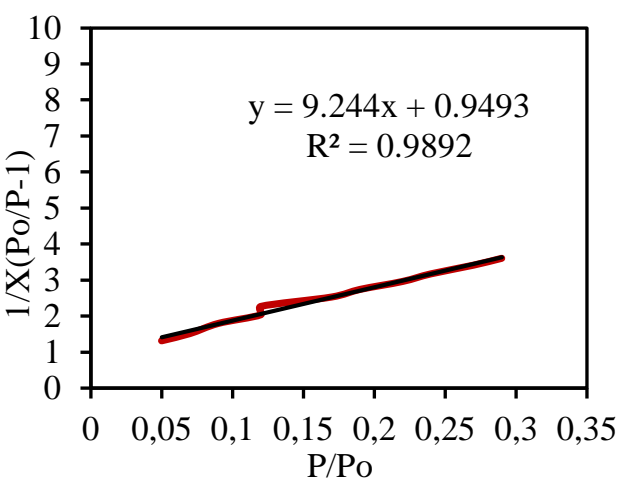

(b)

Gambar 4. Grafik plot BET sampel A (2,5M) dan B (3,5M). 
Tabel 2. Nilai luas permukaan spesifik nanosilika batu apung.

\begin{tabular}{cccccc}
\hline No & Sampel & Slope & Intercept & $\mathrm{Xm}$ & $\mathrm{St}\left(\mathrm{m}^{2} / \mathrm{g}\right)$ \\
\hline 1. & $\mathrm{~A}$ & 24,18 & 0,181 & 0,04104921 & 178,695 \\
2. & $\mathrm{~B}$ & 23,30 & 0,087 & 0,04275879 & 186,137 \\
\hline
\end{tabular}

Dari Tabel 2 luas permukaan spesifik nanosilika yang dihasilkan cukup optimum jika dibandingkan dengan hasil ekstraksi [5] sekitar $98 \mathrm{~m}^{2} / \mathrm{g}$. Dari hasil tersebut konsentrasi $\mathrm{NaOH}$ mempengaruhi karakteristik nanosilika yang dihasilkan. Semakin besar $\mathrm{NaOH}$ luas permukaan yang dihasilkan semakin besar. Luas permukaan berbanding terbalik dengan ukuran partikel. Maka nanosilika yang dihasilkan semakin kecil [9].

\section{KESIMPULAN}

Berdasarkan hasil dan pembahasan dapat disimpulkan bahwa nanosilika yang dihasilkan dari hasil ekstraksi batu apung memiliki fasa amorf dengan kemurnian sebesar 75,84\%. Berdasarkanuji TEM, nanostruktursilikabatuapungmemilikiukura nbutiranpartikel sebesar(11,32 $\pm 0,922) \mathrm{nm}$. Semakin besar konsentrasi $\mathrm{NaOH}$ yang digunakan maka luas permukaan yang dihasilkan semakin besar dan ukuran partikel semakin kecil.

\section{UCAPAN TERIMAKASIH}

Penulis mengucapkan terimakasih kepada Kepala Laboratorium Fisika Material Universitas Lampung, UPT Laboratorium Terpadu dan Sentra Inovasi Teknologi Universitas Lampung, Jurusan Fisika FMIPA Universitas Negeri Padang, Laboratorium Pusat Sains dan Teknologi Bahan Maju-BATAN Serpong, Jurusan Kimia FMIPA Universitas Gadjah Mada Yogyakarta, dan Laboratorium Instrument Teknik Kimia Institut Teknologi Bandung.

\section{DAFTAR PUSTAKA}

[1] L., Monalisa, "Pengaruh Suhu Variasi Annealing terhadap Struktur dan Ukuran Butir Silika dari Abu Tongkol Jagung Menggunakan X-Ray Diffractometer". (Skripsi). Universitas Negeri Padang. Padang. p.45. 2013.

[2] S., Sudrajat, A., Adjat, S. Supriatna, dan M., Arifin, Pasir Kuarsa: Bahan Galian Industri. Pusat Penelitian dan Pengembangan Mineral. p. 260-279. 1997.

[3] R., Balgis, A., Purwanto, S.,Winardi, H., Setyawan, and S., Affandi, "A Faccile Method for Production of High-Purity Silica Xerogels from Bagasse Ash". Advanced Powder Technology. 20. p. 468-472. 2009.

[4] J. A., Katili, dan P., Marks, Geologi. Bandung. Pertjetakan Kilamadju. p. 68. 1969.

[5] K. Srivastava, N. Shringi, V. Devra, and A. Rani, "Pure Silica Extraction from Perlite: Its Characterization and Affecting factors," vol. 2, no. 7, pp. 2936-2942, 2013.

[6] M. N. Sepehr, M. Zarrabi, H. Kazemian, A. Amrane, K. Yaghmaian, and H. R. Ghaffari, "Removal of hardness agents, calcium and magnesium, by natural and alkaline modified pumice stones in single and binary systems," Appl. 
Surf. Sci., vol. 274, pp. 295-305, 2013.

[7] R. Abraham, S. Sanal, J. Thomas, J. George, and D. P. Koruthu, "Silica nano particles synthesized from boiler spent ash: Value addition to an industrial waste," vol. 6, no. 6, pp. 93-99, 2014.

[8] J. L., Gole, and M. G., White, "Nanocatalysis: Selective Conversion of Ethanol to Acetaldehyde Using MonoAtomically Dispersed Copper on Silica Nanospheres". Journal of Catalysis. 204. p. 249-252. 2001.
[9] S., Horikoshi, and N., Serpone, "Microwaves in Naoparticle Synthesis, First Edition". Germany. Wiley VCH Verlag GMBH. p. 3. 2013.

[10] J. Ye et al., "Nanoscratch evaluation of adhesion and cohesion in $\mathrm{SiC} /$ low-k / Si stacked layers Nanoscratch evaluation of adhesion and cohesion in SiC Õ low-k Õ Si stacked layers," vol. 3704, 2014. 